\title{
Influence of Zn Content on Microstructures, Mechanical Properties and Stress Corrosion Behavior of AA5083 Aluminum Alloy
}

\author{
Zhixiong Zhu ${ }^{1} \cdot$ Xingxu Jiang $^{1} \cdot$ Gang Wei $^{1} \cdot$ Xiaogang Fang $^{1} \cdot$ Zhihong Zhong $^{1} \cdot$ Kuijing Song $^{1} \cdot$ Jian Han $^{2}$. \\ Zhengyi Jiang ${ }^{3}$
}

Received: 18 November 2019 / Revised: 14 April 2020 / Published online: 15 May 2020

(C) The Chinese Society for Metals (CSM) and Springer-Verlag GmbH Germany, part of Springer Nature 2020

\begin{abstract}
To enhance the stress corrosion cracking (SCC) resistance, Zn was utilized as an alloy element to add in the AA5083 aluminum alloys. The effects of $\mathrm{Zn}$ content on the microstructures, mechanical properties and SCC resistance were systematically evaluated. The results demonstrate that in the studied range adding $\mathrm{Zn}$ can significantly improve the SCC resistance of the AA5083 alloys. This is related to the relatively low amount of continuous $\beta\left(\mathrm{Al}_{3} \mathrm{Mg}_{2}\right)$ phase along grain boundary and the formation of $\mathrm{Zn}$-containing phase such as $\mathrm{Al}_{5} \mathrm{Mg}_{11} \mathrm{Zn}_{4}$ phase. Based on the results, the optimal Zn content with respect to SCC resistance is approximately $0.50 \mathrm{wt}$ \% . Further increasing $\mathrm{Zn}$ content results in coarse precipitates discontinuously distributed along grain boundaries.
\end{abstract}

Keywords AA5083 aluminum alloy $\cdot$ Slow strain rate test $\cdot$ Precipitation $\cdot$ Stress corrosion cracking

\section{Introduction}

The AA5083 aluminum alloy has been widely used as structural material in the industry of marine, aerospace, shipbuilding and automobile, due to its desirable properties such as excellent formability, corrosion resistance and weldability and high strength-to-weight ratio [1,2]. It is known that AA5083 alloy cannot be strengthened through heat treatment [3]. The main strengthening mechanisms in AA5083 alloy are solution strengthening and strain hardening deriving from $\mathrm{Mg}$ element [4].

Available online at http://link.springer.com/journal/40195.

Zhixiong Zhu

zhuzx@hfut.edu.cn

Zhengyi Jiang

mei9206@hotmail.com

1 School of Materials Science and Engineering, Hefei University of Technology, Hefei 230009, China

2 School of Materials Science and Engineering, Tianjin University of Technology, Tianjin 300384, China

3 School of Mechanical Engineering and Automation, University of Science and Technology Liaoning, Anshan 114051, China
However, the relatively high $\mathrm{Mg}$ content, i.e., 3.5-5 wt.\% or even higher, and the resultant supersaturated of $\mathrm{Mg}$ in the AA5083 alloy lead to the formation of $\beta\left(\mathrm{Al}_{3} \mathrm{Mg}_{2}\right)$ phase when it is exposed to an elevated high temperature for a long time [5]. This type of phase preferably precipitates out at the grain boundaries and continuously distributes along the boundaries. The $\beta$ phase has a more negative potential and is anodic to $\alpha-\mathrm{Al}$ matrix, which can be easily corroded in saline environment [6]. Hence, the AA5083 alloy is sensitive to the stress corrosion cracking (SCC) in some occasion. This issue will undoubtedly restrict its application, especially in the corrosive environment.

Over the past decades, numerous attempts have been made on AA5083 alloy to improve the strength and corrosion resistance through adding micro-alloying elements such as $\mathrm{Sc}, \mathrm{Zr}, \mathrm{Er}$ and $\mathrm{Sr}[7,8]$. For instance, some researchers found that alloying with $\mathrm{Sc}$ or complex alloying with $\mathrm{Sc}$ and $\mathrm{Zr}$ was effective to restrict the formation of $\beta$ phase due to the formation of $\mathrm{Al}_{3} \mathrm{Sc}$ or $\mathrm{Al}_{3}(\mathrm{Sc}, \mathrm{Zr})$ phase $[9,10]$. Fang et al. [11] and Lin et al. [12] claimed that the effect of Er on SCC resistance was similar to that of Sc. Yang et al. [13] also found that micro-alloying with $\mathrm{Er}$ and $\mathrm{Zr}$ gave rise to very fine precipitation of $\mathrm{Al}_{3}(\mathrm{Er}, \mathrm{Zr})$. This was beneficial to both mechanical and corrosion properties.

However, the alloying elements of $\mathrm{Sc}, \mathrm{Zr}$ and $\mathrm{Er}$ are rather expensive, which limits their wide applications. Recently, 
$\mathrm{Zn}$ has been regarded as a candidate of alloying element to improve the corrosion properties of AA5083 alloy. Yang et al. [14] found that adding $0.7 \mathrm{wt} . \% \mathrm{Zn}$ in the AA5083 alloy enhanced the corrosion properties, while Meng et al. [15] stated that the alloy with $1 \mathrm{wt} . \% \mathrm{Zn}$ content exhibited improved intergranular corrosion resistance. So far, the research on adding Zn in AA5083 regarding SCC resistance is few. The optimal alloy design of $\mathrm{Zn}$ in AA5083 is still unclear. Hence, it is imperative to investigate the influence of $\mathrm{Zn}$ content on the microstructure and SCC resistance of AA5083 alloy and thus explore the optimal $\mathrm{Zn}$ content and the mechanisms behind.

Slow strain rate test (SSRT) is selected for this investigation because it provides a quantitative measurement that can be used as an indicator of SCC susceptibility [16]. One advantage of SSRT is the shorter testing time and good reproducibility. This technique is effective at initiating SCC because the continuous application of dynamic strain facilitates SCC initiation and propagation. Moreover, this technique can quickly acquire the informative data regarding SCC susceptibility, e.g., strength loss, ductility loss, SCC susceptibility index, in the environment that is very close to the service condition. Combined with the scanning electron microscopy (SEM) used to examine the fractured surfaces, SSRT can be very powerful technique for the investigation of SCC properties in alloys.

In this context, for better understanding the significance of $\mathrm{Zn}$ on the microstructures and SCC resistance in 5XXX aluminum alloy, a series of AA5083 alloys with various $\mathrm{Zn}$ contents were investigated. The microstructures and precipitation behavior were observed. Meanwhile, the tensile test and SSRT were performed to assess the mechanical properties and SCC resistance. The influence of $\mathrm{Zn}$ content on SCC resistance is discussed.

\section{Experimental}

The investigated materials are the hot-rolled AA5083 aluminum alloy sheets with various $\mathrm{Zn}$ contents. It should be noted that the processing parameters during casting and rolling are identical to ensure the accuracy of this investigation. The chemical composition of the AA5083 alloys is given in Table 1.
After cutting and polishing, the samples were etched in Keller reagent and then examined using optical microscopy $(\mathrm{OM})$ and SEM. To characterize the microstructure in detail, electron backscatter diffraction (EBSD) and transmission electron microscopy (TEM) were performed. Afterwards, microhardness measurements were carried out with a load of $100 \mathrm{~g}$ and a dwelling time of $15 \mathrm{~s}$.

Prior to the tensile test, the specimens were grounded and ultrasonically cleaned. The tensile test was conducted at room temperature with a rate of $6.7 \times 10^{-3} \mathrm{~s}^{-1}$. Every test was repeated at least three times in order to ensure the effectiveness and reproducibility. The specimens for SSRT were placed on a specimen holder in the Hastelloy container. The SSRT was conducted at strain rate of $10^{-6} \mathrm{~s}^{-1}$ in simulated seawater, i.e., 3.5 wt. $\% \mathrm{NaCl}$ aqueous solution, and in air condition, respectively. The average of two values obtained from two specimens was taken. The morphologies of the fractured surfaces after tensile test and SSRT were observed by SEM. Atomic force microscope (AFM) was used to measure the surface potential of the samples. The conductivity test was carried out at $20^{\circ} \mathrm{C}$. The average value of five measurements was regarded as the conductivity of the tested samples.

\section{Results}

\subsection{Microstructures}

The typical microstructure of the AA5083 alloy is shown in Fig. 1. The microstructures mainly consisted of grains with "rod-like" shape, and the grain sizes were approximately $50 \mu \mathrm{m}$ in the rolling direction (RD) and approximately $8 \mu \mathrm{m}$ in the transverse direction (TD) and normal direction (ND). The average grain size is rather uniform (approximately $10 \mu \mathrm{m})$. During the rolling process, the as-cast microstructures disappeared and the recrystallization occurred at the finish rolling temperature of $320^{\circ} \mathrm{C}$. The proper rolling processing played a dominant role in refining the grain size and produced relatively fine and homogeneous microstructure.

Figure 2 displays the SEM micrographs and the SEM-EDS (energy-dispersive spectroscopy) analyses of the AA5083 alloys with various $\mathrm{Zn}$ contents. For the $\mathrm{Zn}$ free alloy, a large amount of secondary phase continuously precipitated out along the grain boundaries (Fig. 2a). The
Table 1 Chemical composition of the studied AA5083 alloys with various $\mathrm{Zn}$ contents (wt.\%)

\begin{tabular}{llllllll}
\hline Alloy No. & $\mathrm{Zn}$ & $\mathrm{Mg}$ & $\mathrm{Mn}$ & $\mathrm{Cr}$ & $\mathrm{Si}$ & $\mathrm{Fe}$ & $\mathrm{Al}$ \\
\hline 1 & 0.00 & 4.47 & 0.70 & 0.152 & $<0.02$ & $<0.02$ & Bal. \\
2 & 0.25 & 4.50 & 0.70 & 0.152 & $<0.02$ & $<0.02$ & Bal. \\
3 & 0.50 & 4.48 & 0.71 & 0.146 & $<0.02$ & $<0.02$ & Bal. \\
4 & 0.75 & 4.49 & 0.68 & 0.151 & $<0.02$ & $<0.02$ & Bal. \\
\hline
\end{tabular}



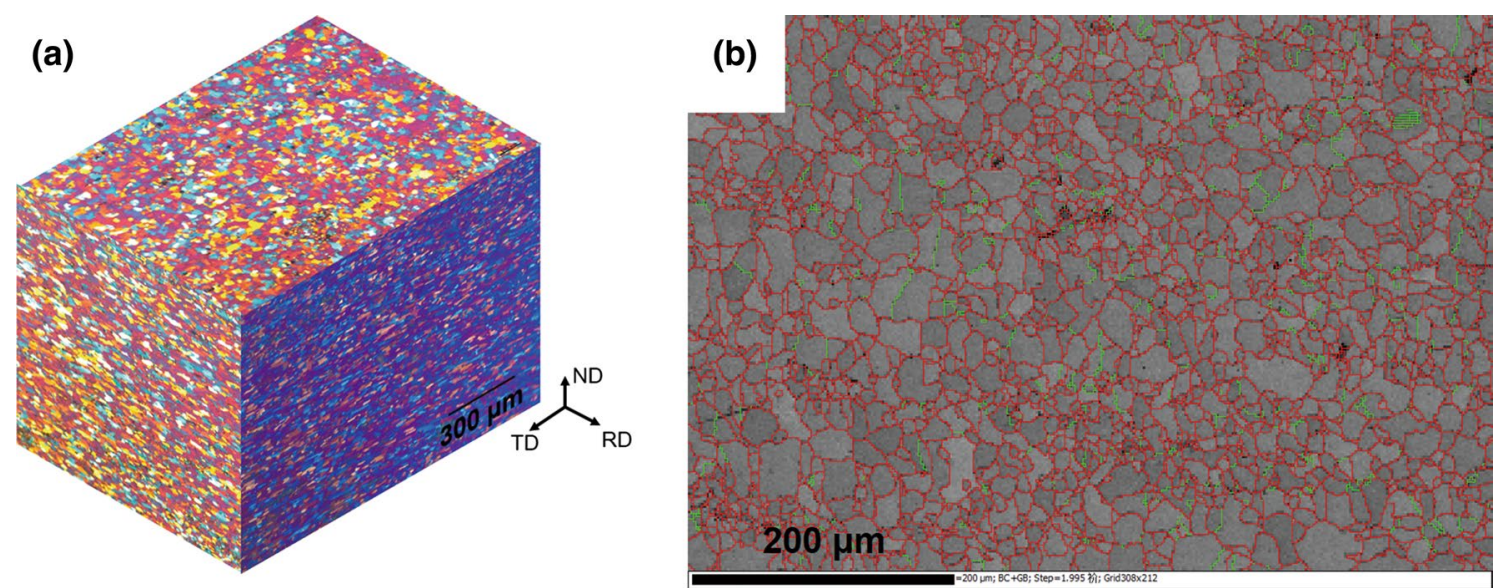

Fig. 1 Typical microstructure of the AA5083 alloy ( $0.25 \%$ Zn content): a three-dimensional micrograph, b band contrast map imposed on grain boundary map
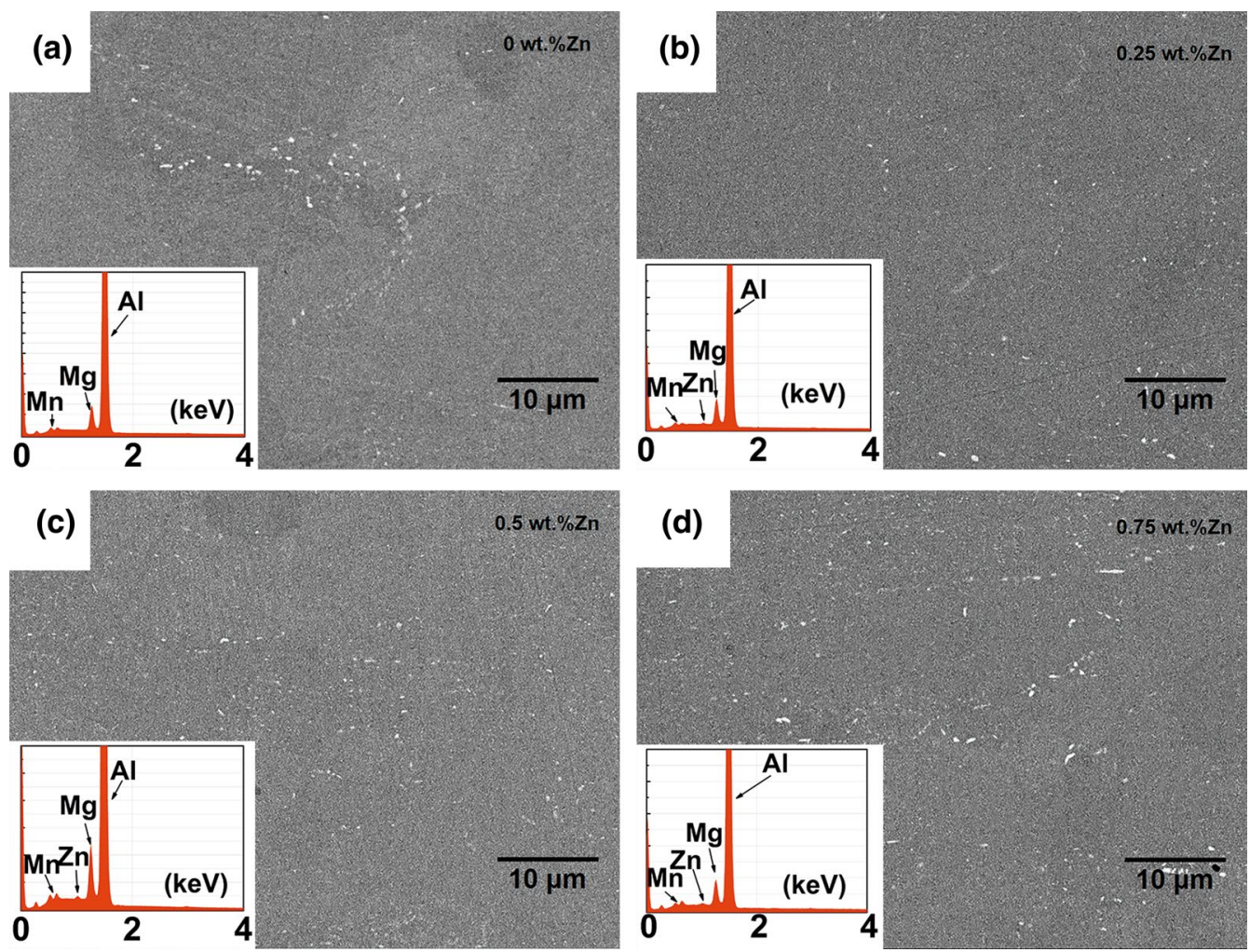

Fig. 2 SEM micrographs and the corresponding EDS analyses of the AA5083 alloys with various Zn contents: a $0 \%$, b $0.25 \%$, c $0.50 \%$, d $0.75 \%$ (in wt.\%)

corresponding SEM-EDS analysis (Fig. 2a) showed that the precipitates contained elements of $\mathrm{Al}, \mathrm{Mg}$ and $\mathrm{Mn}$, which probably was $\beta\left(\mathrm{Al}_{3} \mathrm{Mg}_{2}\right)$ phase and $\mathrm{T}\left(\mathrm{Al}_{18} \mathrm{Mg}_{3} \mathrm{Mn}_{2}\right)$ phase. With $0.25 \mathrm{wt} . \% \mathrm{Zn}$ content, the amount of precipitates distributed at the grain boundaries decreased (Fig. 2b). Compared to the $0.25 \mathrm{wt} . \% \mathrm{Zn}$-containing alloy, more intragranular precipitates were uniformly distributed in the $0.50 \mathrm{wt} . \%$
Zn-containing alloy. Further increasing $\mathrm{Zn}$ content to 0.75 wt. $\%$, some relatively coarse precipitates $(0.5-2 \mu \mathrm{m})$ were found along the grain boundaries. Based on the SEM-EDS analyses (Fig. 2b-d), the precipitates in the Zn-modified alloys contained elements of $\mathrm{Al}, \mathrm{Mg}, \mathrm{Mn}$ and $\mathrm{Zn}$.

The precipitation in the studied AA5083 alloys was characterized by using TEM. The bright-field (BF) images of 
typical precipitates, as well as the corresponding diffraction patterns and TEM-EDS analyses, are presented in Fig. 3. For the Zn-free alloy, it was found that the particles with long strip shape precipitated out along the grain boundaries. Some typical precipitates were identified to be $\mathrm{T}\left(\mathrm{Al}_{18} \mathrm{Mg}_{3} \mathrm{Mn}_{2}\right)$ phase based on the selected area electron diffraction (SAED) pattern (Fig. 3b). Meanwhile, some $\beta$ $\left(\mathrm{Al}_{3} \mathrm{Mg}_{2}\right)$ phase should also be present, which is common in AA5083 alloy.

For the 0.25 wt.\% Zn-containing alloy, some fine precipitates formed in the intergranular. $\mathrm{Al}_{5} \mathrm{Mg}_{11} \mathrm{Zn}_{4}$ phase was identified by the SAED pattern (Fig. 3e) and evidenced by the TEM-EDS analysis (Fig. 3f). Additionally, precipitates containing elements of $\mathrm{Al}$ and $\mathrm{Mn}$ were accidentally detected, evidenced by the TEM-EDS analysis (Fig. 3g). This should be $\mathrm{Al}_{6} \mathrm{Mn}$ phase, which is one type of preexisting particles commonly found in 5XXX alloys [17].

For the $0.50 \mathrm{wt} . \% \mathrm{Zn}$-containing alloy, less precipitates were found along the grain boundaries while more fine precipitates formed in the intragranular (Fig. 3h, i). The results of TEM-EDS analyses showed that the typical precipitates in the 0.50 wt. $\% \mathrm{Zn}$-containing alloy contained $\mathrm{Al}, \mathrm{Mg}, \mathrm{Mn}$ and $\mathrm{Zn}$, which was consistent with the SEM-EDS analysis (Fig. 3j). It was inferred that $\mathrm{Zn}$-containing phases, such as $\mathrm{Al}_{5} \mathrm{Mg}_{11} \mathrm{Zn}_{4}$ and $\tau\left(\mathrm{Mg}_{32}(\mathrm{Al}, \mathrm{Zn})_{49}\right)$ phases, probably existed.

Further increasing $\mathrm{Zn}$ content to $0.75 \mathrm{wt} . \%$, the precipitates became coarse and discontinuous, preferably distributed along grain boundaries (Fig. 3k). The presence of $\beta$ $\left(\mathrm{Al}_{3} \mathrm{Mg}_{2}\right)$ phase could be verified by the SAED pattern in Fig. 31. Moreover, the TEM-EDS analysis of some precipitates also supported the formation of $\mathrm{Zn}$-containing phases.

\subsection{Mechanical Properties}

The Vickers microhardness and tensile tests were conducted for the AA5083 alloys with various $\mathrm{Zn}$ contents. The Vickers hardness, yield strength, tensile strength and elongation of the alloys are summarized in Table 2. The hardness test showed that no significant variation in the Vickers hardness (within a very tight range of $84-88 \mathrm{HV}_{0.1}$ ) was found as a function of $\mathrm{Zn}$ content in the studied range. The tensile strength in TD ranged from 277 to $295 \mathrm{MPa}$ for the alloys with various $\mathrm{Zn}$ contents. The tensile strength of the 0.25 wt.\% Zn-containing alloy was slightly lower than the others, which was possibly due to less precipitation hardening. The elongation of the alloys with $\mathrm{Zn}$ contents of $0-0.50 \mathrm{wt} . \%$ was $23 \%-25 \%$ and exhibited excellent ductility, while the relative high $\mathrm{Zn}$ content of $0.75 \mathrm{wt} . \%$ led to slightly lower elongation (18\%). This could be associated with the appearance of coarse precipitation in the $0.75 \mathrm{wt} . \% \mathrm{Zn}$-containing alloy. Overall, the mechanical properties of the alloys with various $\mathrm{Zn}$ contents were satisfied with the specification of
AA5083 aluminum alloy. The hardness and tensile properties slightly fluctuated with the variation of $\mathrm{Zn}$ content. This could be related to the nearly identical processing parameters and grain size.

Figure 4 shows the typical SEM images of the fractured surfaces after tensile test. The fracture mode in the studied samples was ductile with evidence of plenty of fine dimples on the fractured surfaces. Besides, some secondary phase embedded in some large dimples, which was found to be more frequent in the $0.75 \mathrm{wt} . \% \mathrm{Zn}$-containing alloy (Fig. 4d). This was possibly due to the relatively coarse precipitates in this alloy. It was interesting to found that the fractography was well consistent with the elongation obtained from the tensile test.

\subsection{Stress Corrosion Behavior}

To evaluate the stress corrosion behavior of the studied AA5083 alloys, the SSRT was employed to investigate the influence of $\mathrm{Zn}$ content on the susceptibility to SCC in the AA5083 alloys. Figure 5 shows the SSRT load-displacement curves of the AA5083 alloys with various $\mathrm{Zn}$ contents. The results are summarized in Table 3. It was found that the variation of $\mathrm{Zn}$ content had significant influence on the ultimate tensile strength (UTS) and elongation. Among the studied alloys with various $\mathrm{Zn}$ contents, the alloy with 0.50 wt.\% $\mathrm{Zn}$ content exhibited the maximum elongation (34\%), UTS (323 MPa) and breaking time (130 h) in $3.5 \mathrm{wt} . \% \mathrm{NaCl}$ aqueous solution. The others showed lower elongation, UTS and shorter breaking time. The breaking time for the $\mathrm{Zn}$ free alloy, $0.25 \mathrm{wt} . \%$ and $0.75 \mathrm{wt} . \% \mathrm{Zn}$-containing alloys was $81 \mathrm{~h}, 96 \mathrm{~h}$ and $88 \mathrm{~h}$, respectively. In air condition, the elongation values of the alloys sharply increased compared to that in $\mathrm{NaCl}$ solution. However, the increment of the UTS values was different. Specifically, the alloy with relatively high $\mathrm{Zn}$ content $(0.75$ wt. \%) exhibited $10 \%$ increment in UTS, while others showed approximately $2 \%-3 \%$ increment in UTS. This was probably related to the precipitation. Additionally, the breaking time in air condition was dramatically extended compared to that in $\mathrm{NaCl}$ solution. The $\mathrm{Zn}$-bearing alloys exhibited longer breaking time than the $\mathrm{Zn}$-free alloy.

\subsection{Fracture Surfaces of SSRT Specimens}

Figure 6 displays the typical SEM images of the fractured surfaces after SSRT (in $\mathrm{NaCl}$ solution) for the alloys with various $\mathrm{Zn}$ contents. The fractured surface of the $0.50 \mathrm{wt} . \%$ Zn-containing alloy exhibited very fine dimples, suggesting the ductile fracture mode. Higher or lower $\mathrm{Zn}$ content resulted in coarse dimples, indicating the lower SCC resistance. Some cracks were found in the $\mathrm{Zn}$-free alloy, which could be associated with the segregation. The observation 

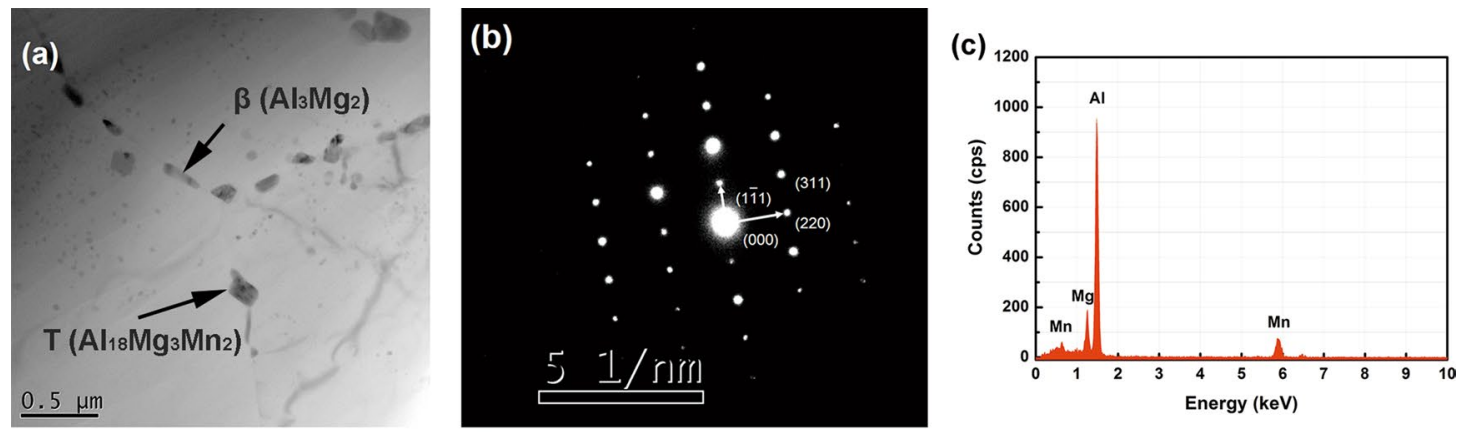

(d)
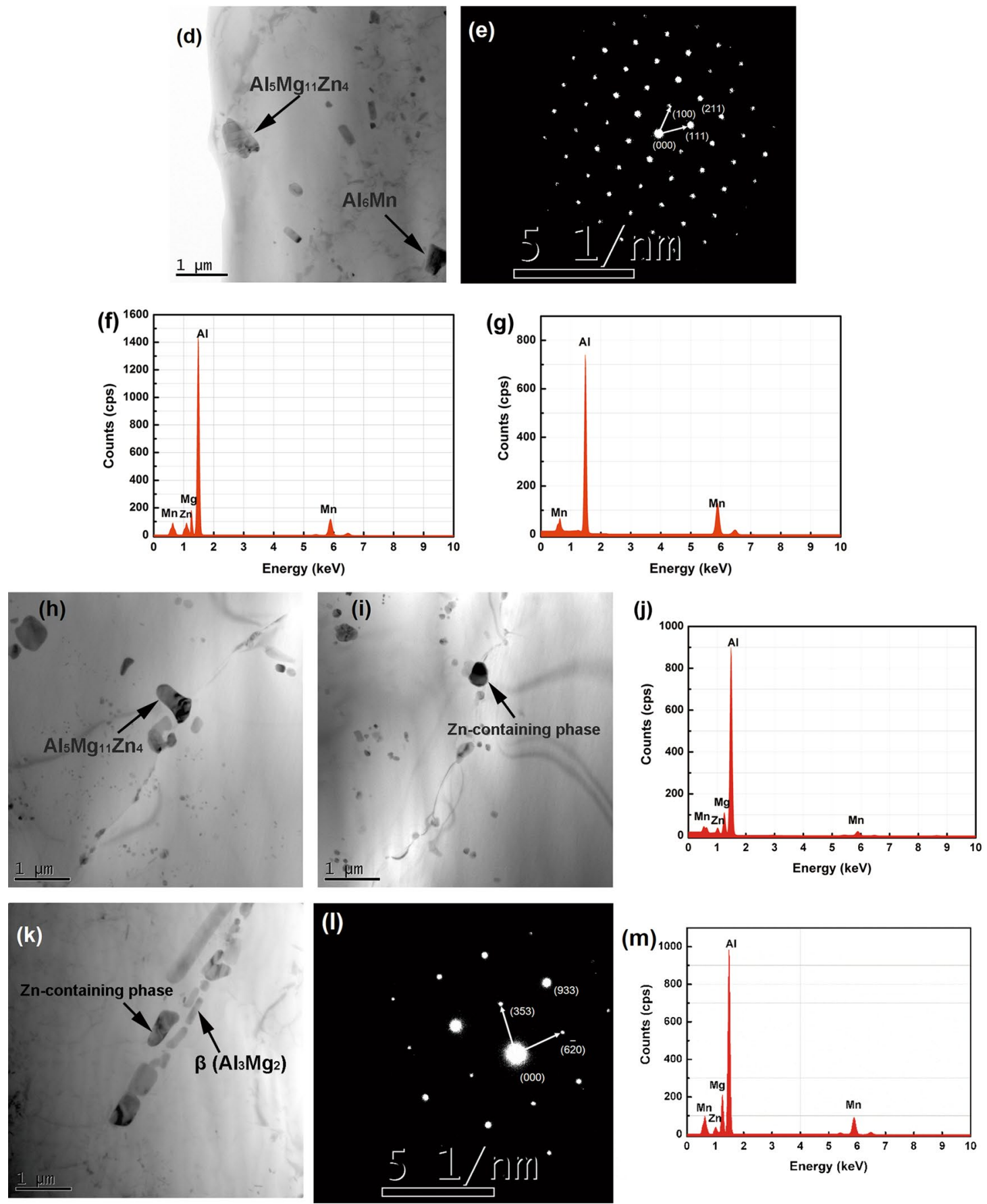

Fig. 3 TEM characterization of typical precipitates in the AA5083 alloys with various $\mathrm{Zn}$ contents: a-c $0 \%, \mathbf{d}-\mathbf{g} 0.25 \%, \mathbf{h}-\mathbf{j} 0.50 \%$, $\mathbf{k}-\mathbf{m} 0.75 \%$ (in wt.\%) 
Table 2 Mechanical properties and tensile properties of the AA5083 alloys with various $\mathrm{Zn}$ contents

\begin{tabular}{lllll}
\hline Zn (wt.\%) & $\begin{array}{l}\text { Hardness } \\
(\text { HV0.1 })\end{array}$ & $\begin{array}{l}\text { Yield strength } \\
(\mathrm{MPa})\end{array}$ & $\begin{array}{l}\text { Tensile } \\
\text { strength } \\
(\mathrm{MPa})\end{array}$ & $\begin{array}{l}\text { Elon- } \\
\text { gation } \\
(\%)\end{array}$ \\
\hline 0 & 88 & 168 & 295 & 23 \\
0.25 & 88 & 155 & 277 & 25 \\
0.50 & 84 & 162 & 295 & 23 \\
0.75 & 87 & 160 & 285 & 18 \\
\hline
\end{tabular}

of the fracture surface after SSRT was well consistent with the results in Table 3 .

\subsection{Surface Potential and Conductivity Measurements}

The surface potential measured by AFM (Table 4) showed that the mean potential values of the $\mathrm{Zn}$-bearing alloys were considerably higher than that of the $\mathrm{Zn}$-free alloy. The alloy with $0.50 \mathrm{wt} . \%$ showed the highest mean potential $(1.26 \mathrm{~V})$ among the studied alloys. Figure 7 shows the conductivity of the studied AA5083 alloys with various $\mathrm{Zn}$ contents. The conductivity of the Zn-bearing alloys was higher than that of the $\mathrm{Zn}$-free alloy, which could indicate the positive effect of $\mathrm{Zn}$ on the corrosion properties of the AA5083 alloy.

\section{Discussion}

\subsection{Correlation between Microstructure, Mechanical Properties and Zn Content}

For the alloys with various $\mathrm{Zn}$ contents, the microstructures consisted of relatively fine grains with some precipitates distributed in the $\alpha$-Al matrix. The grain size is the key factor related to the mechanical properties. In the present work, the processing parameters for the studied alloys are identical, which can keep similar grain size and matrix microstructure. It can be seen from Fig. 1 that the average grain size after rolling is approximately $8 \mu \mathrm{m}$. The grain refinement is beneficial to the mechanical properties. Thus, the matrix microstructure can contribute grain refinement strengthening to the strength. Besides, the main alloying element in AA5083 alloy is $\mathrm{Mg}$, which can provide precipitation hardening and solution strengthening to a considerable degree. The precipitation hardening can be evidenced by the appearance of $\mathrm{Al}-\mathrm{Mg}-\mathrm{Mn}$ precipitates and $\mathrm{Al}-\mathrm{Mg}$ precipitates (Fig. 3). The $\mathrm{Zn}$ concentrations are relatively low (maximum 0.75
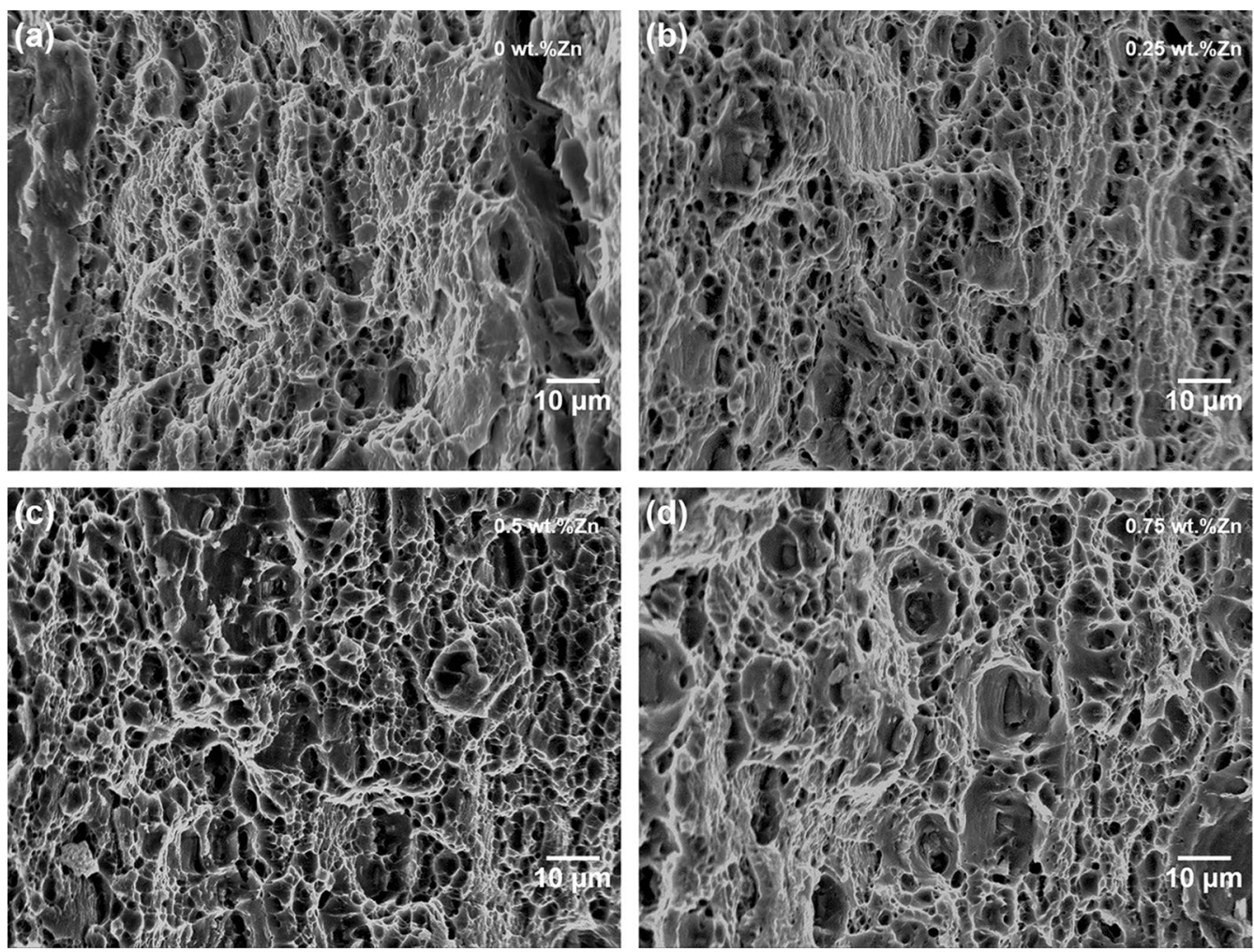

Fig. 4 SEM images of the fractured surfaces after tensile tests of the AA5083 alloys with various Zn contents: a $0 \%$, b $0.25 \%$, c $0.50 \%$, d $0.75 \%$ (in wt.\%) 

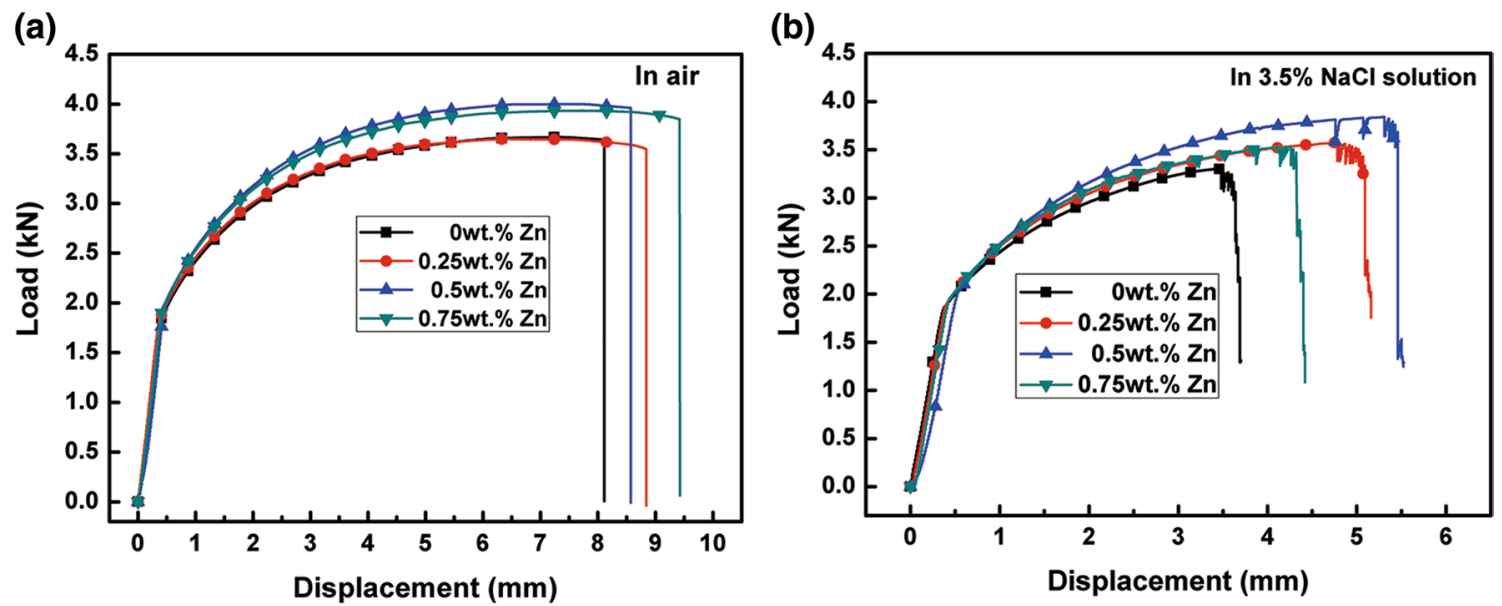

Fig. 5 SSRT load-displacement curves of the studied AA5083 alloys tested in different conditions: a in air, b in $3.5 \mathrm{wt} \% \mathrm{NaCl}$ solution

Table 3 UTS, elongation and breaking time of the AA5083 alloys with various $\mathrm{Zn}$ contents obtained from SSRT

\begin{tabular}{|c|c|c|c|c|c|c|}
\hline \multirow[t]{2}{*}{$\overline{Z n(w t . \%)}$} & \multicolumn{2}{|c|}{ Strength $(\mathrm{MPa})$} & \multicolumn{2}{|c|}{ Elongation (\%) } & \multicolumn{2}{|c|}{ Breaking time (h) } \\
\hline & In air & In $3.5 \% \mathrm{NaCl}$ & In air & In $3.5 \% \mathrm{NaCl}$ & In air & In $3.5 \% \mathrm{NaCl}$ \\
\hline 0 & 310 & 301 & 35 & 15 & 147 & 81 \\
\hline 0.25 & 307 & 298 & 39 & 19 & 161 & 96 \\
\hline 0.50 & 330 & 323 & 44 & 34 & 156 & 130 \\
\hline 0.75 & 328 & 297 & 47 & 18 & 172 & 88 \\
\hline
\end{tabular}
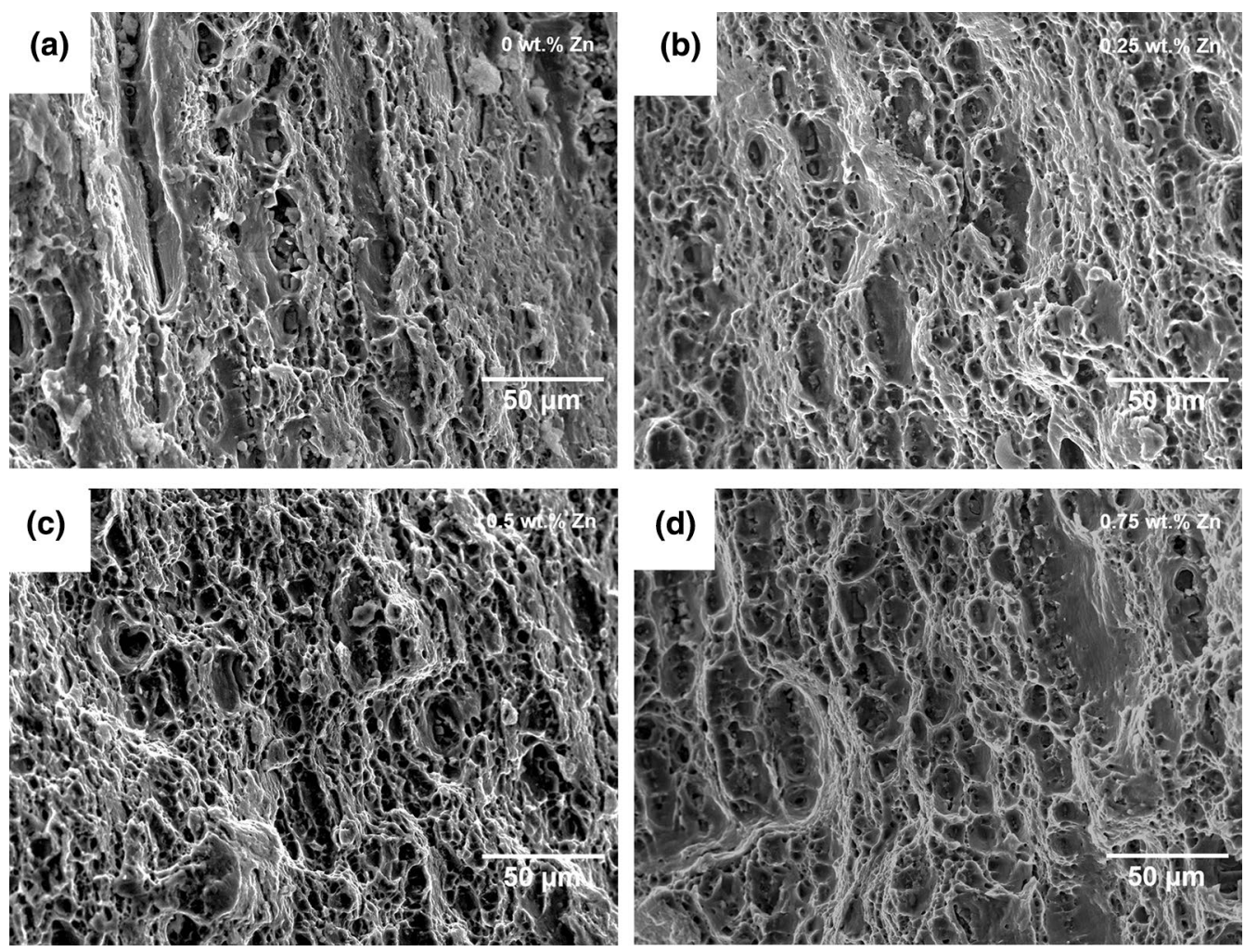

Fig. 6 Fractured surfaces (SSRT in $3.5 \mathrm{wt} \% \mathrm{NaCl}$ aqueous solution) of the AA5083 alloys with various $\mathrm{Zn}$ contents: a $0 \%$, b $0.25 \%$, c $0.50 \%$, d $0.75 \%$ (in wt. \%) 
Table 4 Surface potential of the AA5083 alloys with various $\mathrm{Zn}$ contents

\begin{tabular}{ll}
\hline Zn (wt.\%) & Potential $(\mathrm{V})$ \\
\hline 0 & 0.94 \\
0.25 & 1.22 \\
0.50 & 1.26 \\
0.75 & 1.13 \\
\hline
\end{tabular}

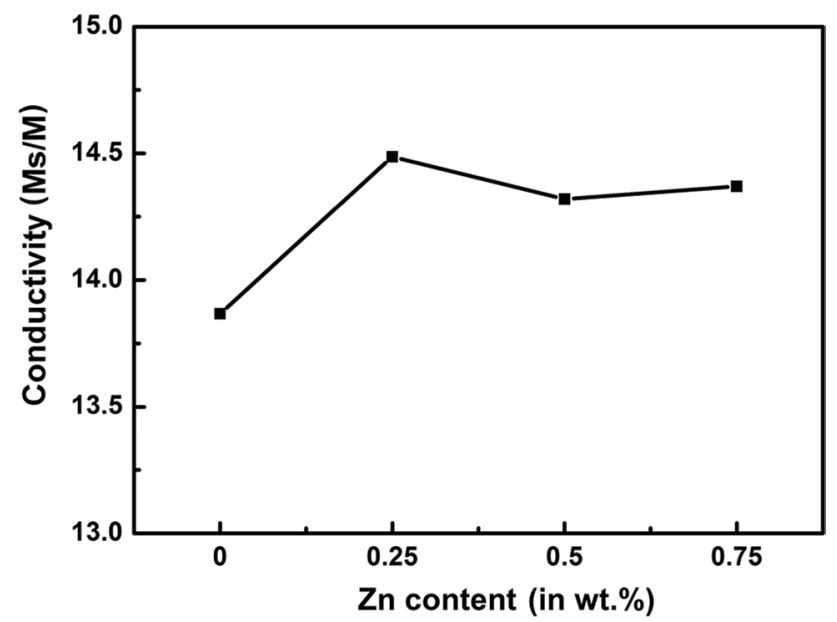

Fig. 7 Conductivity as a function of $\mathrm{Zn}$ content in the AA5083 alloys

wt.\%) and thus have no significant influence on the fluctuation of mechanical properties.

\subsection{Effects of Zn Content on the SCC Susceptibility of AA5083 Alloy}

The SCC susceptibility of the aluminum alloys with various $\mathrm{Zn}$ contents was evaluated by SSRT in both air and $3.5 \mathrm{wt} . \%$ $\mathrm{NaCl}$ aqueous solution. To assess the SCC behavior, the elongation loss $I_{\delta}$, strength loss $\sigma_{\delta}$ and the ratio of breaking time $t$ were defined [18]. Moreover, the important indicator of SCC susceptibility $I_{\mathrm{SSRT}}$ is also defined, which simultaneously considers both strength and elongation. It should be noted that the SCC susceptibility gradually increased when the SCC susceptibility index varied from 0 to 1 [19].

$I_{\delta}=\left(1-\varepsilon_{\mathrm{c}} / \varepsilon_{\mathrm{a}}\right) \times 100 \%$,

$\sigma_{\delta}=\left(1-\sigma_{\mathrm{c}} / \sigma_{\mathrm{a}}\right) \times 100 \%$,

$t=t_{\mathrm{c}} / t_{\mathrm{a}} \times 100 \%$,

$I_{\mathrm{SSRT}}=1-\left[\sigma_{\mathrm{c}}\left(1+\varepsilon_{\mathrm{c}}\right)\right] /\left[\sigma_{\mathrm{a}}\left(1+\varepsilon_{\mathrm{a}}\right)\right]$,

where $\varepsilon_{\mathrm{c}}$ is the elongation at fracture of the alloy in the corrosive environment and $\varepsilon_{\mathrm{a}}$ is the elongation at fracture in air, $\sigma_{\mathrm{c}}$ is the strength at fracture of the alloy in the corrosive environment, $\sigma_{\mathrm{a}}$ is the strength at fracture in air, $t_{\mathrm{c}}$ is breaking time in corrosive environment and $t_{\mathrm{a}}$ is breaking time in air.

The elongation loss $I_{\delta}$, strength loss $\sigma_{\delta}$, the ratio of breaking time $t$ and SCC susceptibility $I_{\mathrm{SSRT}}$ are calculated and the results are given in Table 5. It can be found that the $0.50 \mathrm{wt} . \% \mathrm{Zn}$-containing alloy exhibits lower values of elongation loss $I_{\delta}$, strength loss $\sigma_{\delta}$ and SCC susceptibility index $I_{\mathrm{SSRT}}$, while higher value of the breaking time ratio $t$. It strongly supports that the $0.50 \mathrm{wt} . \% \mathrm{Zn}$-containing alloy has the lowest SCC susceptibility.

From Table 5, it may be noted that the difference of strength loss for the studied alloys is rather slight. This is well consistent with the microstructural analyses that the constituent structure consists of fine grain size (approximately $8 \mu \mathrm{m}$ ) and large amount of precipitates (mainly $\mathrm{Al}-\mathrm{Mg}-\mathrm{Mn}$ precipitates). The grain refinement and precipitation strengthening contributed large proportion of the total strength. The various $\mathrm{Zn}$ contents in the studied range may not lead to the large variation in the total amount of precipitation. This is the reason why the strength loss of the alloys with various $\mathrm{Zn}$ contents is not substantial. Additionally, it should be noted that the strength loss of the alloy with relatively high $\mathrm{Zn}$ content $(0.75 \mathrm{wt} . \%)$ is larger than the others, which is probably due to the relatively coarse precipitates and thus the less precipitation strengthening effect.

Overall, from the viewpoint of the SCC comparison (Table 5), the results clearly demonstrate that the 0.50 wt.\% $\mathrm{Zn}$ content is the optimal content and dramatically improves the SCC resistance of the studied AA5083 alloys without the sacrifice of strength. On the other hand, from the view of absolute values of elongation and breaking time (Table 3), it is obvious that adding $\mathrm{Zn}$ is advantageous to the SCC resistance of the AA5083 alloys. These results are well consistent with the Carroll's report [20]. Moreover, in the corrosive environment (i.e., in $\mathrm{NaCl} 3.5$ wt.\% solution), the beneficial effect of $\mathrm{Zn}$ is more profound than that in air condition. This is due to that the aqueous environment is one key factor leading to SCC [21].

Table 5 Elongation loss $I_{\delta}$, the strength loss $\sigma_{\delta}$, the ratio of breaking time $t$ and SCC index $I_{\text {SSRT }}$ of the AA5083 alloys with various $\mathrm{Zn}$ contents

\begin{tabular}{lllll}
\hline $\mathrm{Zn}(\mathrm{wt} . \%)$ & $I_{\delta}$ & $\sigma_{\delta}$ & $t$ & $I_{\text {SSRT }}$ \\
\hline 0 & 0.57 & 0.03 & 0.55 & 0.17 \\
0.25 & 0.51 & 0.03 & 0.60 & 0.17 \\
0.50 & 0.23 & 0.02 & 0.83 & 0.09 \\
0.75 & 0.62 & 0.09 & 0.51 & 0.27 \\
\hline
\end{tabular}




\subsection{SCC Mechanisms of AA5083 Alloy}

For aluminum alloys, there are two extremes of the range of SCC behavior that is observed [22]. One is the active dissolution of an anodic phase from grain boundary responsible for SCC [23], while the other is hydrogen induced SCC [24]. The two mechanisms have been reported to be involved in 5XXX aluminum alloys. When the alloys are exposed to the corrosive environment (e.g., $\mathrm{NaCl}$ solution), it is supposed that the pits firstly occur and form corrosion paths. The dissolution of pitting-corroded areas leads to hydrolytic acidification.

In this study, a large amount of precipitates continuously distributed at the grain boundary of $\alpha-\mathrm{Al}$ matrix in the $\mathrm{Zn}$ free AA5083 alloy (Fig. 3). From the literature review on SCC of Al alloys, the grain boundary precipitation should be the $\beta\left(\mathrm{Al}_{3} \mathrm{Mg}_{2}\right)$ phase. It is known that the $\beta$ phase has a deleterious influence on the SCC resistance. In the $\mathrm{NaCl}$ solution, the dissolution of exposed $\beta$ and $\alpha-\mathrm{Al}$ matrix occurs. Dissolution of $\beta$ phase produces $\mathrm{Al}^{3+}$ and $\mathrm{Mg}^{2+}$, which hydrolyses to activate significant $\alpha$-Al dissolution. This will lead to additional $\mathrm{Al}^{3+}$ hydrolysis and low $\mathrm{pH}$ value, provided the enriched crack solution is not diluted by cation egress [25]. In other words, dissolution of $\beta$ phase triggers dissolution of the $\mathrm{Al}-\mathrm{Mg}$ solid solution around the $\beta$ phase. An acid environment forms at the crack tip when the external or internal stress is loading. This hydrogen can diffuse to the boundaries of $\beta$ phase and matrix, and then the atomic hydrogen is absorbed, leading to hydrogen induced crack growth $[25,26]$.

The studied AA5083 alloys were hot-rolled and then cooled in air to ambient temperature. Thus, the alloys were not subjected to sensitizing at relatively low temperature (usually $\left.100-200{ }^{\circ} \mathrm{C}\right)$. Also, the $\mathrm{T}\left(\mathrm{Al}_{18} \mathrm{Mg}_{3} \mathrm{Mn}_{2}\right)$ and $\mathrm{Al}_{5} \mathrm{Mg}_{11} \mathrm{Zn}_{4}$ phases were identified by the SAED pattern (Fig. 3). In this case, $\mathrm{Mg}$ atoms were partially consumed due to the formation of $\mathrm{T}\left(\mathrm{Al}_{18} \mathrm{Mg}_{3} \mathrm{Mn}_{2}\right)$ phase and $\mathrm{Al}_{5} \mathrm{Mg}_{11} \mathrm{Zn}_{4}$ phase, and the amount of $\beta\left(\mathrm{Al}_{3} \mathrm{Mg}_{2}\right)$ phase was supposed to be reduced. Thus, the studied AA5083 alloys should exhibit relatively high SCC resistance compared to that reported in literatures.

Based on the results, adding $\mathrm{Zn}$ in the AA5083 alloys brings about significant variation on SCC resistance, surface potential and conductibility. In terms of SCC resistance, it is thought that adding $\mathrm{Zn}$ can promote the formation of $\mathrm{Zn}$ containing precipitates, such as $\tau\left(\mathrm{Mg}_{32}(\mathrm{Al}, \mathrm{Zn})_{49}\right)$ phase and $\mathrm{Al}_{5} \mathrm{Mg}_{11} \mathrm{Zn}_{4}$ phase. According to Meng et al. [15], $\mathrm{Zn}$ dramatically decreased the segregation of $\mathrm{Mg}$ atoms and thus decreased the segregation of $\mathrm{Mg}$ and formation of $\beta$ phase at grain boundaries. This is consistent with our experimental results. With the increase in $\mathrm{Zn}$ content from 0 to $0.50 \mathrm{wt} . \%$, the grain boundary precipitates became discontinuous and the amount of this precipitation reduced. Also, some fine precipitates were dispersed in the matrix. Further increasing $\mathrm{Zn}$ content to $0.75 \mathrm{wt} . \%$, the discontinuous grain boundary precipitates became coarse (Figs. 2 and 3), causing the decrease in SCC resistance.

The surface potential of the AA5083 alloys can also reflect the SCC resistance in some degree. Generally, the more negative the potential, the stronger the reducibility. The Zn-modified alloys present higher potential than the $\mathrm{Zn}$-free alloy. According to Yang et al. [14], $\beta$ phase has the most negative potential in this alloy system. As discussed above, adding $\mathrm{Zn}$ deceases the amount of $\beta$ phase and diminishes the $\mathrm{Mg}$ segregation in the $\mathrm{Zn}$-modified alloys. Thus, adding $\mathrm{Zn}$ enhances the surface potential.

Conductivity is a good indicator of SCC resistance. It is known that the conductivity of alloys is closely related to the type, fraction and size of precipitation, which can indirectly reflect the SCC resistance [27, 28]. Higher conductivity usually indicates higher SCC resistance. In this study, Zn obviously enhances the conductivity of the AA5083 alloys. It is known that $\mathrm{Zn}$ promotes the formation of several types of precipitates, and consumes the alloy elements (especially $\mathrm{Mg}$ ) in the solid solution. The less solute elements give rise to higher conductivity. Therefore, the $\mathrm{Zn}$-modified alloys show higher conductivity.

Overall, the correlation between $\mathrm{Zn}$ content and SCC resistance is well established in this study. The SSRT demonstrates that adding $\mathrm{Zn}$ can significantly improve SCC resistance of the AA5083 alloys. The optimal content of $\mathrm{Zn}$ element is $0.50 \mathrm{wt} . \%$ in terms of SCC resistance. Moreover, the surface potential and conductivity can also indirectly support the beneficial effect of $\mathrm{Zn}$ on SCC resistance. However, the surface potential and conductivity may not be quantitative to determine the optimal alloy design of $\mathrm{Zn}$. This is because there are some other factors influencing the potential and conductivity which is out of the scope of this study. But the indication from potential and conductivity on $\mathrm{Zn}$ content regarding SCC resistance is discernible and cannot be ignored.

\section{Conclusions}

In the present study, $\mathrm{Zn}$ was used as an alloying element to modify the AA5083 aluminum alloy. The influence of $\mathrm{Zn}$ content on the microstructures, mechanical properties and SCC resistance was investigated. The following conclusions can be drawn:

1. The influence of $\mathrm{Zn}$ content on the grain size and mechanical properties was not obvious. The grain sizes were approximately $10 \mu \mathrm{m}$ in ND and $50 \mu \mathrm{m}$ in TD and RD. The hardness and tensile strength were in a very 
tight range of $84-88 \mathrm{HV}_{0.1}$ and $277-295 \mathrm{MPa}$, respectively.

2. Adding $\mathrm{Zn}$ changed the type, size and distribution of the precipitates in the AA5083 alloys. For the Zn-free alloy, the main precipitates were $\mathrm{T}\left(\mathrm{Al}_{18} \mathrm{Mg}_{3} \mathrm{Mn}_{2}\right)$ phase and $\beta\left(\mathrm{Al}_{3} \mathrm{Mg}_{2}\right)$ phase, which were continuously or closely spaced along the grain boundaries. Increasing the $\mathrm{Zn}$ contents to $0.50 \mathrm{wt} . \%$ produced $\mathrm{Zn}$-containing phase. The morphologies of the secondary phases were dispersed within the matrix. However, enhancing $\mathrm{Zn}$ to 0.75 wt.\% resulted in the reapparition of coarse precipitates discontinuously distributed along the grain boundaries.

3. The Zn-modified alloys exhibited the improved SCC resistance. Specifically, the AA5083 alloy containing 0.50 wt. $\% \mathrm{Zn}$ showed the highest SCC resistance. This could be attributed to the relatively low amount of continuous grain boundary precipitates and the formation of Zn-containing phase.

The implications of this work are significant in terms of optimal alloy design of 5XXX aluminum alloys for critical applications such as marine components.

Acknowledgements This work is financially supported by the Nature Science Research Project of Anhui Province (No. 1808085QE136), the Anhui Postdoctoral Science Foundation (No. 934269) and the National Natural Science Foundation of China (No. 51905143).

\section{References}

[1] J.K. Brosi, Scr. Mater. 63, 799 (2010)

[2] Y.K. Yang, T.R. Allen, Metall. Mater. Trans. A 44, 5226 (2013)
[3] M. Popović, E. Romhanji, J. Mater. Process. Technol. 125, 275 (2002)

[4] R.H. Jones, D.R. Baer, M.J. Danielson, Metall. Mater. 32, 1699 (2001)

[5] G. Yi, D.A. Cullen, A.T. Derrick, Y. Zhu, E. Sundberg, Corrosion 72, 177 (2015)

[6] R. Zhang, S.P. Knight, R.L. Holtz, R. Goswami, C.H.J. Davies, N. Birbilis, Corrosion 72, 144 (2016)

[7] Y. Zhang, K. Gao, S. Wen, H. Huang, Z. Nie, D. Zhou, J. Alloys Compd. 610, 27 (2014)

[8] Y. Buranova, V. Kulitskiy, M. Peterlechner, A. Mogucheva, R. Kaibyshev, S.V. Divinski, G. Wilde, Acta Mater. 124, 210 (2017)

[9] A.K. Lohar, B. Mondal, D. Rafaja, V. Klemm, S.C. Panigrahi, Mater. Charact. 60, 1387 (2009)

[10] M.K. Cavanaugh, N. Birbilis, R.G. Buchheit, F. Bovard, Scr. Mater. 56, 995 (2007)

[11] H.C. Fang, H. Chao, K.H. Chen, Mater. Sci. Eng. A 610, 10 (2014)

[12] S. Lin, Z. Nie, H. Huang, B. Li, Mater. Des. 31, 1607 (2010)

[13] D. Yang, X. Li, D. He, H. Huang, Mater. Sci. Eng. A 561, 226 (2013)

[14] L. Yang, Dissertation, Central South University, 2012

[15] C. Meng, D. Zhang, L. Zhuang, J. Alloys Compd. 655, 178 (2016)

[16] S.W. Dean, J. ASTM Int. 4, 1 (2007)

[17] P.R. Rios, G.S. Fonseca, Scr. Mater. 50, 71 (2004)

[18] G. Yi, B. Sun, J.D. Poplawsky, Y. Zhu, J. Alloys Compd. 740, 461 (2017)

[19] X. Zhang, L. Zhong, M. Chen, Chin. J. Nonferrous Met. 16, 1743 (2006)

[20] M.C. Carroll, R.G. Buchheit, Mater. Sci. Forum 396, 1443 (2002)

[21] G.V. Boven, W. Chen, Acta Mater. 55, 29 (2007)

[22] T. Burleigh, Corrosion 47, 89 (1991)

[23] G. Scamans, N. Holroyd, Corros. Sci. 27, 329 (1987)

[24] R. Ricker, Metall. Trans. A 19, 1775 (1988)

[25] C.B. Crane, R.P. Gangloff, Corrosion 72, 221 (2015)

[26] R.H. Jones, JOM 55, 42 (2003)

[27] J. Chang, T. Chuang, J. Mater. Eng. Perform. 9, 253 (2000)

[28] R. Goswami, G. Spanos, P. Pao, Mater. Sci. Eng. A 527, 1089 (2010) 